Jurnal Keperawatan Silampari

Volume 4, Nomor 2, Juni 2021

e-ISSN: 2581-1975

p-ISSN: 2597-7482

DOI: https://doi.org/10.31539/jks.v4i2.1635

\title{
ANALISIS FAKTOR YANG MEMPENGARUHI KEPATUHAN MENJALANKAN DIET PADA LANSIA PENDERITA DIABETES MELLITUS TIPE DUA
}

\author{
Zeilen Fitriana $^{1}$, Eka Asvista Salviana ${ }^{2}$ \\ Universitas Negeri Semarang ${ }^{1,2}$ \\ onlyvina3@gmail.com ${ }^{1}$
}

\begin{abstract}
ABSTRAK
Penelitian ini bertujuan untuk mengetahui faktor yang mempengaruhi kepatuhan diet pada pasien diabetes mellitus tipe II diantaranya dukungan keluarga, pengetahuan, pendapatan serta konseling gizi. Metode penelitian yang digunakan dalam penelitian ini adalah cross sectional. Hasil dari penelitian ini menunjukan adanya hubungan dari dukungan keluarga, pengetahuan, pendapatan dan konseling gizi terhadap kepatuhan diet pada orang lanjut usia yang mengalami penyakit diabetes millitus tipe II pada tahun 2019 pada sebuah Kabupaten di Jambi. Simpulan, terdapat hubungan dukungan keluarga, pengetahuan, pendapatan dan konseling gizi terhadap kepatuhan diet pada orang lanjut usia yang mengalami penyakit diabetes millitus tipe II.
\end{abstract}

Kata Kunci: Diabetes Melitus, Dukungan Keluarga, Pengetahuan, Konseling Gizi

\begin{abstract}
This study aims to determine the factors that affect dietary compliance in patients with type II diabetes mellitus, including family support, knowledge, income, and nutritional counseling. The research method used in this study is cross-sectional. This study indicates a relationship between family support, understanding, revenue, and nutritional counseling on dietary compliance in older people with type II diabetes Mellitus in 2019 in a district in Jambi. In conclusion, there is a relationship between family support, knowledge, income, and nutritional counseling on dietary compliance in older people with type II diabetes Mellitus.
\end{abstract}

Keywords: Diabetes Mellitus, Family Support, Knowledge, Nutrition Counseling

\section{PENDAHULUAN}

Lansia merupakan salah satu kelompok atau populasi berisiko yang semakin meningkat jumlahnya. Lansia mengalami masalah kesehatan antara lain kelemahan dan kemunduran fisik, kognitif, mental dan sosial yang bisa menyebabkan lansia lebih berisiko dan rentan terhadap suatu penyakit (Andri et al., 2019). Beberapa penyakit tidak menular pada lansia diantaranya hipertensi, stroke, radang sendi atau rematik, asam urat, dan diabetes mellitus (Harsismanto et al., 2020; Andri et al., 2020). Data terbaru dari International Diabetes Federation tahun 2017 menunjukkan bahwa Indonesia saat ini menduduki peringkat ke-6 dunia dengan jumlah penderita diabetes terbesar, yaitu sebanyak 10,3 juta jiwa (Depkes RI, 2018; Sartika et al., 2020; Setyawati et al., 2020). Hasil Riset Kesehatan Dasar, Riskesdas tahun 2018 menunjukkan bahwa 
prevalensi penderita diabetes naik mejadi 8,5 persen, dari 6,9 persen. Provinsi Jambi salah satu provinsi yang ada di Indonesia dengan prevalensi diabetes mellitus yang terus meningkat. Data di wilayah Provinsi Jambi menunjukkan bahwa pada tahun 2017 terdapat 2268 penderita diabetes mellitus dan pada tahun 2018 menjadi sebanyak 3696 penderita diabetes mellitus (Dinkes Provinsi Jambi, 2018).

Diabetes mellitus dikategorikan menjadi empat tipe yaitu diabetes mellitus tipe-1, diabetes mellitus tipe-2, diabetes mellitus gestational dan diabetes mellitus tipe lain yang disebabkan oleh faktor-faktor lain. Diabetes mellitus tipe-2 adalah jenis yang paling umum dari diabetes mellitus. Diabetes tipe-2 ditandai dengan cacat progresif dari fungsi sel- $\beta$ pankreas yang menyebabkan tubuh kita tidak dapat memproduksi insulin dengan baik. Diabetes mellitus tipe-2 terjadi ketika tubuh tidak lagi dapat memproduksi insulin yang cukup untuk mengimbangi terganggunya kemampuan untuk memproduksi insulin. Pada diabetes mellitus tipe-2 tubuh kita baik menolak efek dari insulin atau tidak memproduksi insulin yang cukup untuk mempertahankan tingkat glukosa yang normal (Kartini et al., 2018).

Terapi diet merupakan terapi utama dalam penatalaksanaan diabetes melitus, diet yang sehat dapat mengurangi perkembangan penyakit diabetes mellitus (Depkes RI, 2018). Diet ditujukan terutama untuk mengendalikan berat badan pasien, khususnya penderita diabetes mellitus tipe dua dengan obesitas, karena penurunan berat badan merupakan kunci dalam penanganan diabetes mellitus tipe-2 (Dinkes Tanjung Jabung, 2018). Penting diperhatikan dalam diet adalah jumlah kalori yang dibutuhkan oleh masing-masing individu, bukan jumlah banyaknya makan, hal ini bertujuan untuk mendapatkan kontrol metabolik, lipid dan tekanan darah (Dinkes Prov Jambi, 2018).

Kepatuhan dalam menjalankan diet dapat sangat sulit di lakukan dan membutuhkan faktor-faktor yang mendukung agar kepatuhan dapat berhasil. Beberapa faktor yang mempengaruhi kepatuhan dalam diet adalah dukungan keluarga, pengetahuan, pendapatan serta konseling gizi.

Penelitian yang dilakukan Pudyasti et al., (2017) menunjukkan bahwa lansia yang memiliki dukungan keluarga dalam kategori kurang yaitu sebanyak (7,5\%). Hal ini menunjukkan dukungan keluarga yang diberikan kepada lansia masih belum optimal dikarenakan banyak anggota keluarga yang sibuk dengan pekerjaannya sehingga kurang memperhatikan lansia untuk memenuhi kebutuhannya secara mandiri. Dukungan keluarga merupakan salah satu faktor yang mempengaruhi ketaatan pasien dalam menjalankan diet.

Penelitian sebelumnya sudah pernah dilakukan, tapi faktor yang diteliti hanya fokus pada beberapa faktor saja. Namun pada penelitian iniberfokus pada dukungan keluarga, pengetahuan, penghasilan dan konseling gizi terhadap kepatuhan diet bagi penderita diabetes mellitus tipe-2 di Provinsi Jambi pada tahun 2019.

\section{METODE PENELITIAN}

Penelitian ini menggunakan pendekatan cross sectional. Populasi dalam penelitian ini adalah lanjut usia yang terdiri dari 16 puskesmas di Kabupaten Tanjung Jabung Barat dengan jumlah populasi secara keseluruhan 2003 (dua ribu tiga) orang penderita diabetes mellitus. Sampel pada penelitianzini menggunakan stratified random sampling, sampelsyang didapatkanhsebesar 333 orang.

Variabel dependen dalam penelitian ini adalah kepatuhan diet bagi penderita diabetes mellitus tipe-2, sedangkan variabelnindependentndalam penelitiannini adalah dukungan keluarga, pengetahuan, penghasilan dan konseling gizi. Pada penelitian ini 
menggunakan data primer yaitu pemberian kuisioner. Pengumpulan data dengan menggunakan instrument kuesioner dengan pertanyaan tertutup. Kuesioner dalam penelitian ini adalah angket dukungan keluarga, pengetahuan, penghasilan dan konseling gizi. Setelah itu data primer di uji validitas dan reliabilitaskan terlebih dahulu. Selanjutnya data skunder yaitu tentang penderita diabetes mellitus tipe-2 di 16 puskesemas Kabupaten Tanjung Jabung. Sebelum mengumpulkan data, peneliti mengurus ethical clearance di Universitas Negeri Semarang. Teknik analisis data pada penelitian ini menggunakan analisis univariat, bivariat menggunakan uji chi square dan analisis multivariat meggunakan regresi logistik.

\section{HASIL PENELITIAN}

Tabel 1.

Distribsui Frekuensi Kepatuhan Diet

Penderita Diabetes Mellitus tipe 2

\begin{tabular}{lcc}
\hline \multicolumn{1}{c}{ Jenis } & Frekuensi & Persentase (\%) \\
\hline Kepatuhan Diet & & \\
1. Ya & 177 & 53,2 \\
2. Tidak & 156 & 46,8 \\
\hline Dukungan Keluarga & & \\
1. Baik & 222 & 66,7 \\
2. Kurang & 111 & 33,3 \\
\hline Pengetahuan & & \\
1. Baik & 204 & 61,3 \\
2. Kurang & 129 & 38,7 \\
\hline Pendapatan & & \\
1. Tinggi & 219 & 65,8 \\
2. Rendah & 114 & 34,2 \\
\hline Konseling Gizi & & \\
1. Sering & 207 & 62,2 \\
2. Jarang & 126 & 37,8 \\
\hline
\end{tabular}

Berdasarkan tabel 1 didapatkan bahwa sampel kepatuhan diet lebih banyak yaitu sebesar 53\% dari sampel. Dari data hasil univariat terlihat bahwa dukungan keluarga dan pengetahuan responden tergolong baik. Sedangkan status ekonomi pada responden di salah satu kabupaten di Provinsi Jambi dalam penelitian ini tergolong tinggi sedangkan untuk konseling gizi pada sampel lebih dari 50\%. Hal tersebut dikarenakan peneliti lebih dapat menghubungi responden yang sering konseling gizi karena tenaga kesehatan mempunyai kontaknya.

Tabel. 2

Hasil Uji Chi Square

Faktor Kepatuhan Diet

\begin{tabular}{|c|c|c|c|c|}
\hline \multirow{2}{*}{ Jenis } & \multicolumn{2}{|c|}{ Kepatuhan Diet } & \multirow{2}{*}{ P Value } & \multirow{2}{*}{ OR $(95 \%$ CI $)$} \\
\hline & Tidak & $\mathrm{Ya}$ & & \\
\hline \multicolumn{5}{|l|}{ Dukungan Keluarga } \\
\hline 1. Kurang Baik & 61 & 50 & 0,036 & $1,631(1,031-2,580)$ \\
\hline 2. Baik & 95 & 127 & & \\
\hline \multicolumn{5}{|l|}{ Pengetahuan } \\
\hline 1. Kurang Baik & 70 & 59 & 0,031 & $1,628(1,044-2,538)$ \\
\hline 2. Baik & 86 & 118 & & \\
\hline
\end{tabular}




\begin{tabular}{|c|c|c|c|c|}
\hline \multicolumn{5}{|l|}{ Penghasilan } \\
\hline 1. Rendah & 76 & 38 & 0,000 & $3,475(2,157-5,598)$ \\
\hline 2. Tinggi & 80 & 139 & & \\
\hline \multicolumn{5}{|l|}{ Konseling Gizi } \\
\hline 1. Jarang & 82 & 44 & 0,000 & $3,350(2,107-5,325)$ \\
\hline 2. Sering & 74 & 133 & & \\
\hline
\end{tabular}

Berdasarkan tabel 2 hasil dari uji chi square untuk melihat hubungan dukungan keluarga terhadap kepatuhan diet bagi penderita Diabetes Mellitus tipe 2 di Kabupaten Tanjung Jabung Barat pada tahun 2019 yang diuji dengan uji chi square didaptkan bahwa P-Value sebesar 0,036 yang artinya kurang dari nilai signifikani yang diterapkan pada penelitian ini yaitu sebesar 0,05 . Hal itu berarti terdapat hubungan antara dukungan keluarga dengan kepatuhan diet. Terdapat hubungan tersebut, jika dilihat dari statistik frekuensinya dukungan keluarga yang baik mengakibatkan kepatuhan dalam berdiet.

Tabel. 3

Rangkuman Uji Regresi Logistik Ganda

\begin{tabular}{lccccc}
\hline \multicolumn{1}{c}{ Variabel } & B & Wald & P & OR & 95\% CI \\
\hline $\begin{array}{l}\text { Dukungan } \\
\text { Keluarga }\end{array}$ & 0,525 & 3.9 & 0,046 & 1,69 & $1,010-2,829$ \\
\hline Pengetahuan & 0,424 & 2.7 & 0,095 & 1,52 & $0,929-2,511$ \\
\hline Penghasilan & 1,405 & 38,0 & 0,000 & 4,07 & $2,423-6,858$ \\
\hline Konseling Gizi & 1,479 & 31,9 & 0,000 & 4,38 & $2,627-7,328$ \\
\hline Constant & $-2,320$ & $\begin{array}{c}37,20 \\
\text { Log likelihood }=392,121 \\
\text { Nagelkerke } \mathrm{R}^{2}=27,7 \%\end{array}$ & 0,098 & \\
\hline
\end{tabular}

\section{PEMBAHASAN}

Dari tabel 1 didapatkan bahwa sampel kepatuhan diet lebih banyak yaitu sebesar 53\% dari sampel. Dari data hasil univariat terlihat bahwa dukungan keluarga dan pengetahuan responden tergolong baik. Sedangkan status ekonomi pada responden di salah satu kabupaten di Provinsi Jambi dalam penelitian ini tergolong tinggi sedangkan untuk konseling gizi pada sampel lebih dari 50\%. Hal tersebut dikarenakan peneliti lebih dapat menghubungi responden yang sering konseling gizi karena tenaga kesehatan mempunyai kontaknya.

Pada tabel 2 hasil dari uji chi square untuk melihat hubungan dukungan keluarga terhadap kepatuhan diet bagi penderita diabetes mellitus tipe-2 di kabupaten Tanjung Jabung Barat pada tahun 2019 yang diuji dengan uji chi square didaptkan bahwa PValue sebesar 0,036 yang artinya kurang dari nilai signifikani yang diterapkan pada penelitian ini yaitu sebesar 0,05 . Hal itu berarti terdapat hubungan antara dukungan keluarga dengan kepatuhan diet. Terdapat hubungan tersebut, jika dilihat dari statistik frekuensinya dukungan keluarga yang baik mengakibatkan kepatuhan dalam berdiet.

Sejalan dengan penelitian Bistara \& Ainiyah (2018) menunjukan bahwa dari 30 penderita DM sebagian besar pengetahuannya baik tentang diet DM. Pengetahuan tersebut berkaitan dengan penatalaksanaan DM meliputi keterlibatan dalam kegiatan penyuluhan, melakukan latihan fisik atau olah raga, pengobatan dan diet " $3 \mathrm{~J}$ " yang terdiri dari jenis makanan, jumlah dan jadwal makan serta komplikasi DM. Pengetahuan tersebut diharapkan dapat diimplementasikan dalam kehidupan sehari-hari bagi penderita DM sehingga penderita DM dapat mengatasi bila ada gejala dan keluhan, mempertahankan rasa nyaman, pengendalian gula darah dan mencegah komplikasi. 
Pada tabel 2 pengetahuan penderita responden diabetes mellitus tipe- 2 yang diuji dengan uji chi square didaptkan bahwa P-Value sebesar 0,031 yang artinya kurang dari nilai signifikan yang diterapkan pada penelitian ini yaitu sebesar 0,05 . Hal itu berarti terdapat hubungan pengetahuan dengan kepatuhan diet. Terdapat hubungan tersebut, jika dilihat dari statistik frekuensinya pengetahuan yang baik mengakibatkan kepatuhan dalam berdiet. Sejalan dengan penelitian yang dilakukan Haryono et al., (2020) menunjukkan bahwa nilai rata-rata pengetahuan pada kelompok intervensi lebih besar dari kelompok kontrol dengan nilai $\mathrm{p}$ value $=0,000$. Hal ini berarti terdapat pengaruh yang signifikan pemberian pendidikan kesehatan terhadap tingkat pengetahuan tentang diet DM pada responden yang mendapatkan intervensi dibandingkan dengan kelompok kontrol.

Pada hasil uji statistik yang menunjukan bahwa pengetahuan berhubungan dengan kepatuhan berdiet, karena responden dengan pengetahuan yang baik memiliki managemen resiko terburuk jika melakukan hal yang tidak benar. Hal tersebut membuat responden dengan pengetahuan baik rajin dalam melakukan diet supaya sembuh dari penyakit tersebut. Hal tersebut sesuai dengan penelitian Hestina (2017) menunjukkan responden yang berjenis kelamin perempuan memiliki risiko dua kali lebih besar terhadap rendahnya kepatuhan dalam pengelolaan diet. Dalam penelitiannya juga dapat disimpulkan bahwa proporsi kepatuhan pengelolaan diet pada responden perempuan lebih tinggi dibandingkan laki-laki. Perbedaan jenis kelamin dalam melakukan pengelolaan diet tidak menjadi suatu masalah. Karena responden yang berjenis kelamin perempuan maupun laki-laki sangat penting untuk melakukan pengelolaan diet agar dapat mencegah timbulnya komplikasi. Penelitian lain yang tidak sejalan adalah menurut Nugroho \& Handono (2017) menyatakan dalam penelitiannya bahwa tidak ada hubungan yang bermaknsa antara jenis kelamin dengan kepatuhan diet penderita DM dengan jumlah laki-laki sebanyak $77 \%$ lebih patuh daripada perempuan sebanyak $50,8 \%$ patuh.

Penelitian Isnaeni et al., (2018) didapatkan dari total 40 responden, sebagian besar pengetahuan responden adalah baik sebanyak 24 responden $(60 \%)$ dan sisanya kecil memiliki pengetahuan kurang sebanyak 16 responden (40\%). Hal ini terlihat dari kemampuan mayoritas responden dalam menjawab benar pertanyaan tentang diet DM. Responden yang berpengetahuan baik adalah responden yang berpendidikan menengah atas yang termasuk ke dalam kelompok pendidikan tinggi. Sehingga responden yang berpendidikan tinggi memiliki kemampuan dalam menyerap informasi lebih cepat dan menggali informasi tentang pola diet DM tipe-2.

Pada tabel 2 terlihat hasil dari hubungan penghasilan responden dengan kepatuhan diet, pada tabel 2 hasil analisis menunjukan hasi uji chi square, didapatkan P-Value sebesar 0,000 yang artinya kurang dari nilai segnifikansi sebesar 0,05, sehingga hal ini dapat disimpulkan bahwa ada hubungan antara status penghasilan dengan kepatuhan diet.

Pada hasil di atas menujukan terdapat hubungan antara penghasilan dengan kepatuhan diet. Hal tersebut karena penghasilan yang cukup membuat responden lebih sering konsul, karena mereka mempunyai cukup dalam membiayai konsul, sehingga mereka mendapatkan pengetahuan cara untuk sembuh dalam penyakit diabetes mellitus tipe-2. Tidak hanya itu penderita diabetes mellitus tipe- 2 dengan pendapatan yang rendah lebih tidak patuh dibanding yang mempunyai pendapatan tinggi. 
Selanjutnya masih pada tabel 2, terlihat hasil dari hubungan konseling gizi dengan kepatuhan diet, pada tabel 2 hasil analisis menunjukan hasi uji chi square, didapatkan PValue sebesar 0,000 yang artinya kurang dari nilai segnifikansi sebesar 0,05, sehingga hal ini dapat disimpulkan bahwa ada hubungan antara konseling gizi dengan kepatuhan diet.

Dari penelitian diatas peneliti menyimpulkan bahwa dukungan keluarga yang kurang akan mengakibatkan kesehatan pada penderita DM terganggu. Namun jika sebaliknya keluarga memberikan dukungan pada penderita diabetes mellitus, penderita akan termotivasi untuk mematuhi diet diabetes mellitus apabila mengingat terapi dan perawatan DM memerlukan waktu yang cukup lama sehingga dapat menimbulkan kebosanan pada pasien DM terutama pada pasien lansia. Oleh karena itu selain memperhatikan masalah fisik maka perlu juga memperhatikan faktor psikologis pasien dalam menyelesaikan masalah diabetes mellitus. Keikutsertaan anggota keluarga dalam memandu pengobatan, diet, latihan jasmani dan pengisian waktu luang yang positif. Keluarga merupakan bentuk peran serta aktif bagi keberhasilan penatalaksanaan diabetes mellitus (Jamaludin \& Choirunisa, 2019). Pada hasil di atas menujuka terdapat hubungan antara konseling gizi dengan kepatuhan diet. Hal tersebut karena dalam analisis sebelumnya dukungan keluarga serta pengetahuan membuat responden mempunyai motivasi untuk sembuh.

Dari tabel 3 terlihat pengaruh yang paling besar adalah pada konseling gizi dengan OR sebesar 4,38. Hal tersebut karena penderita diabetes mellitus yang mengikuti penyuluhan gizi secara rutin lebih patuh dalam diet. peneliti berpendapat bahwa kualitas interaksi tenaga kesehatan dengan pasien merupakan bagian penting dalam menentukan derajat kepatuhan. Sejalan dengan penelitian Santoso \& Susilowati (2018) hasil analisis menunjukkan ada pengaruh pendampingan diet penderita DM di Posyandu Lansia Dharma Husada Insani di Wilayah Kerja Pukesmas Balowerti wilayah Puskesmas Balowerti Kediri terhadapkepatuhan diet dengan arah pengaruh dalam kategori positif. Pendampingan adalah kunci pembuka potensi seseorang untuk memaksimalkan kinerjanya. Lansia yang memiliki kebiasaan atau perilaku diet tidak baik berpeluang memperparah kondisi penyakit diabetes mellitus tipe-2 sebesar 2,9 kali lebih besar dibandingkan dengan lansia yang memiliki kebiasaan dan perilaku diet yang baik (Djamaluddin et al., 2020).

Selain konseling gizi, faktor pengetahuan juga turut berpengaruh dalam menentukan kepatuhan diet seseorang. Dari hasil yang didapat, diketahui bahwa subjek dengan pengetahuan yang baik cenderung lebih mematuhi rekomendasi diet yang diberikan (63,9\%). Hal ini dikarenakan dengan penambahan pengetahuan dapat meningkatkan kemampuan kognitif seseorang (Isnaini \& Saputra, 2017). Aspek pengetahuan diet diabetes mellitus yaitu tentang penyebab, gejala, diet diabetes, jenis dan jadwal (Setyaningrum et al., 2018)

Pada pasien DM perubahan perilaku sangat diperlukan untuk mencapai tujuan dari pengelolaan DM yaitu kadar gula dalam batas normal. Tujuan dari pengelolaan DM tidak akan tercapai tanpa disertai kepatuhan pasien. Kepatuhan (adherence) merupakan adanya keterlibatan pasien secara sukarela dan aktif dalam pengelolaan penyakitnya, serta terdapat pembagian tugas antara tenaga kesehatan dan pasien sehingga keduanya memiliki peran yang sama dalam pengelolaan penyakit (Purwandari \& Susanti, 2017)

Kepatuhan diet pada penelitian ini didapatkan hasil bahwa dari tiga komponen kepatuhan diet (tepat jumlah, jadwal dan jenis) sebagian besar harus memilih jenis-jenis bahan makanan yang sesuai dengan diet DM dalam perilaku makan sehari-hari (Isnaini 
\& Saputra, 2017). Selanjutnya pada nilai Nagelkerke $\mathrm{R}^{2}$ sebesar $27,7 \%$ artinya variabel bebas menjelaskan model sebesar $27,7 \%$ dengan kata lain masih ada variabel yang belum diteliti yang mempengaruhi kepatuhan diet yaitu sebesar $72,2 \%$.

\section{SIMPULAN}

Terdapat hubungan dukungan keluarga, pengetahuan, pendapatan dan konseling gizi terhadap kepatuhan diet pada orang lanjut usia yang mengalami penyakit diabetes millitus tipe II di Kabupaten Tanjung Jabung tahun 2019.

\section{SARAN}

Diharapkan Puskesmas menyediakan media pendidikan kesehatan bagi pasien DM seperti leaflet, lembar balik yang dapat dimanfaatkan untuk penyuluhan kesehatan khususnya tentang diet bagi pasien DM. Penyuluhan kesehatan tentang diet DM dan bekerja sama dengan ahli gizi untuk konseling tentang diet bagi pasien DM dapat meningkatkan kepatuhan pasien DM

\section{DAFTAR PUSTAKA}

Andri, J., Karmila, R., Padila, P., Harsismanto, J., \& Sartika, A. (2019). Terapi Aktivitas Senam Ergonomis terhadap Peningkatan Kemampuan Fungsional Lansia. Journal of Telenursing (JOTING), 1(2), 304-313. https://doi.org/https://doi.org/10.31539/joting.v1i2.933

Andri, J., Padila, P., Sartika, A., Putri, S. E. N., \& Harsismanto, J. (2020). Tingkat Pengetahuan terhadap Penanganan Penyakit Rheumatoid Artritis pada Lansia. Jurnal Kesmas Asclepius, 2(1), 12-21. https://doi.org/https://doi.org/10.31539/jka.v2i1.1139

Bistara, D. N., \& Ainiyah, N. (2018). Hubungan Pengetahuan dengan Kepatuhan Diet pada Penderita Diabetes Melitus di Posyandu Lansia Cempaka Kelurahan Tembok Dukuh Kecamatan Bubutan Surabaya. Jurnal Ilmiah Kesehatan, 11(1), 1-96. http://journal.unusa.ac.id/index.php/jhs/article/view/570

Depkes R. I. (2018). Data dan Informasi Profil Kesehatan Indonesia. Jakarta: Pusat Data dan Informasi Ke-menterian Kesehatan Republik Indonesia

Dinas Kesehatan Tanjung Jabung Barat. (2018). Profil Kesehatan Tanjuung jabung barat Tahun 2018. Dinas Kesehatan Tanjung Jabung Barat

Dinas Kesehatan Provinsi Jambi. (2018). Profil Kesehatan Provinsi Jambi Tahun 2018. Dinas Kesehatan Provinsi Jambi

Djamaluddin, A., Arisandi, W., \& Permatasari, A. (2020). Hubungan Perilaku Diet dengan Kadar Gula Darah pada Lansia Penderita Diabetes Melitus Tipe 2 di Wilayah Kerja Puskesmas Rawat Inap Sukoharjo Kabupaten Pringsewu Tahun 2020. Jurnal Ilmu Kesehatan Indonesia, 1(2), 1-8. http://jurnal.umitra.ac.id/index.php/jikmi/article/view/433

Harsismanto, J., Andri, J., Payana, T, D., Andrianto, M. B., \& Sartika, A. (2020). Kualitas Tidur Berhubungan dengan Perubahan Tekanan Darah pada Lansia. Jurnal Kesmas Asclepius, 2(1), 1-11. https://doi.org/https://doi.org/10.31539/jka.v2i1.1146

Haryono, S., Suryati, E. S., \& Maryam, R. S. (2020). Pendidikan Kesehatan tentang Diet terhadap Kepatuhan Pasien Diabetes Melitus. Jurnal Riset Kesehatan, 7(2), 91-96. https://doi.org/10.31983/jrk.v7i2.3308 
Hestina, D. W. (2017). Faktor-Faktor yang Berhubungan dengan Kepatuhan dalam Pengelolaan Diet pada Pasien Rawat Jalan Diabetes Melitus Tipe 2 di Kota Semarang. Jurnal of Health Education, 2(2), 138-145. https://doi.org/10.15294/jhe.v2i2.14448

IDF, I. D. F. (2017). Idf Diabetes Atlas Eighth Edition 2017. http://fmdiabetes.org/wpcontent/uploads/2018/03/IDF-2017.pdf

Isnaeni, F. N., Risti, K. N., Mayawati, H., \& Arsy, M. K. (2018). Tingkat Pendidikan, Pengetahuan Gizi dan Kepatuhan Diet pada Pasien Diabetes Melitus (DM) Rawat Jalan di RSUD Karanganyar. The Indonesian Journal of Health Promotion, 1(2), 40-45. https://jurnal.unismuhpalu.ac.id/index.php/MPPKI/article/view/116

Isnaini, N., \& Saputra, M. H. A. (2017). Pengetahuan dan Motivasi Meningkatkan Kepatuhan Diet Pasien Diabetes Melitus Tipe II. Jurnal Ilmiah Ilmu-Ilmu Kesehatan, $15(3)$, 136-141. http://jurnalnasional.ump.ac.id/index.php/medisains/article/view/2077

Jamaludin, J., \& Choirunisa, A. (2019). Hubungan Dukungan Keluarga dengan Kepatuhan Diet pada Penderita DM di Ruang Poliklinik RSI Sunan Kudus. Jurnal Profesi Keperawatan, 6(1), 45-60. http://jurnal.akperkridahusada.ac.id/index.php/jpk/article/view/62

Kartini, T. D., Amir, A., \& Sabir, M. (2018). Kepatuhan Diet Pasien DM Berdasarkan Tingkat Pengetahuan dan Dukungan Keluarga di Wilayah Puskemas Sudiang Raya. Jurnal Media Gizi Pangan, 25(1), 55-63. http://journal.poltekkesmks.ac.id/ojs2/index.php/mediagizi/article/view/60

Nugroho, Y, W., \& Handono, N, P. (2017). Hubungan Tingkat Kepatuhan Diet terhadap Kadar Glukosa Darah pada Penderita Diabetes Mellitus di Kelurahan Bulusulur. Jurnal Keperawatan GSH, 6(1), http://journal.akpergshwng.ac.id/index.php/gsh/article/view/39

Pudyasti, B., Sugiyanto, S., \& Suryani, S. (2017). Hubungan Dukungan Keluarga dengan Kepatuhan Diet pada Lansia Penderita Diabetes Melitus di Puskesmas Minggir Sleman Yogyakarta. Dspace Unisa Yogyakarta. http://digilib2.unisayogya.ac.id/xmlui/handle/123456789/1536

Purwandari, H., \& Susanti, S. N. (2017). Hubungan Kepatuhan Diet dengan Kualitas Hidup pada Penderita DM di Poli Penyakit Dalam RSUD Kertosono. STRADA Jurnal Ilmiah Kesehatan, 6(2), 16-21. DOI: https://doi.org/10.30994/sjik.v6i2.3

Santoso, P., \& Susilowati, E. (2018). Pengaruh Pendampingan Diet terhadap Kepatuhan Diet dan Kadar Gula Darah pada Penderita Diabetes Mellitus di Wilayah Puskesmas Balowerti Kota Kediri. Jurnal Ilmu Kesehatan, 6(2), 182-187. https://ejurnaladhkdr.com/index.php/jik/article/view/176

Sartika, A., Betrianita, B., Andri, J., Padila, P., \& Nugrah, A. (2020). Senam Lansia Menurunkan Tekanan Darah pada Lansia. Journal of Telenursing (JOTING), 2(1), 11-20. https://doi.org/https://doi.org/10.31539/joting.v2i1.1126

Setyaningrum, Y., Mardiana, S. S., \& Susanti, D. (2018). Hubungan Tingkat Pendidikan dan Pengetahuan tentang Diet DM dengan Kepatuhan Diet Pasien Diabetes Melitus di RSUD R.A Kartini Jepara. Indonesia Jurnal Perawat, 3(1), 44-50. https://ejr.stikesmuhkudus.ac.id/index.php/ijp/article/view/643

Setyawati, A. D., Ngo, T. H. L., Padila, P., \& Andri, J. (2020). Obesity and Heredity for Diabetes Mellitus among Elderly. JOSING: Journal of Nursing and Health, 1(1), 26-31. https://doi.org/https://doi.org/10.31539/josing.v1i1.1149 